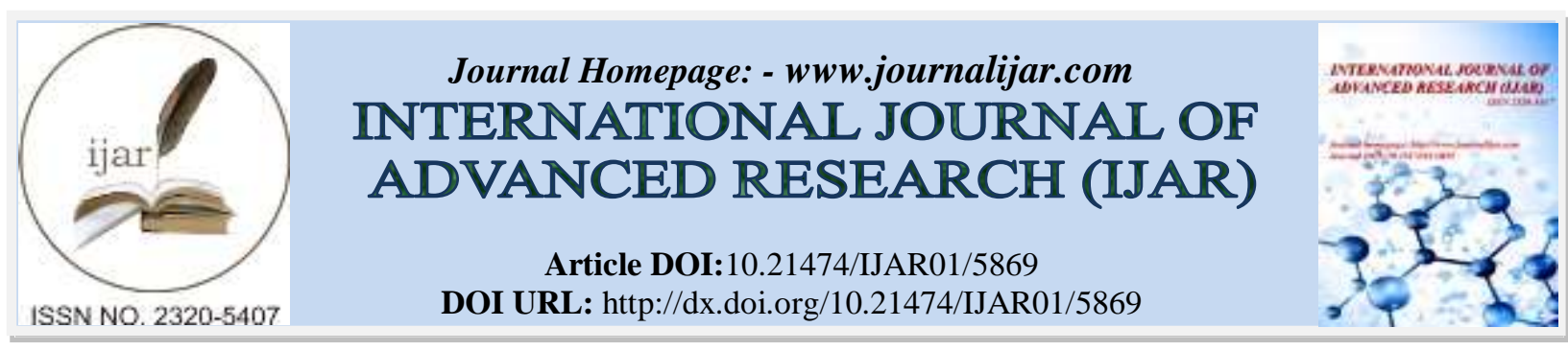

RESEARCH ARTICLE

\title{
SAFETY OF ETHYL ACETATE FRACTION OF COCOS NUCIFERA ROOT EXTRACT.
}

\author{
${ }^{*}$ Maximin Senou ${ }^{1,2}$, Atchade Pascal Tchogou ${ }^{1}$, T.Victorien Dougnon ${ }^{1}$, Cokou Pascal Agbangnan Dossa ${ }^{3}$, \\ Pidox Ogue ${ }^{6}$, Angélique Agossadou ${ }^{1}$, Anatole Laleye ${ }^{4}$, Frédéric Loko ${ }^{1}$, Amegnona Agbonon ${ }^{5}$, Alphonse Sezan ${ }^{6}$ \\ and Lamine Babamoussa? \\ 1. Laboratory in Applied Biology, Polytechnic School of Abomey-Calavi, University of Abomey-Calavi, 01 BP \\ 2009 Cotonou, R. Benin. \\ 2. Laboratory of Experimental and Clinic Biology (LaBEC), Faculty of Sciences and Techniques of Dassa, \\ National University of Sciences, Technologies, Engineering and Mathematics (UNSTIM), R. Benin, BP 14 \\ Dassa-Zoumé. \\ 3. Laboratoire d'Etude et de Recherche en Chimie Appliquée (LERCA); Ecole Polytechnique d'Abomey-Calavi / \\ Université d'Abomey-Calavi (UAC), R. Bénin. \\ 4. Human Biology Unit, Faculty of Health Science, 01 B.P. 188 Cotonou, R. Benin. \\ 5. Laboratoire de Physiologie/Pharmacologie, Faculté des Sciences, Université de Lomé, Togo. \\ 6. Laboratory of Biomembranes and Cellular Signaling, University of Abomey-Calavi 01 BP 188 Cotonou Benin. \\ 7. Laboratoire de Biologie et de Typage Moléculaire en Microbiologie, University of Abomey-Calavi 01 BP 188 \\ Cotonou Benin.
}

\section{Manuscript Info}

Manuscript History

Received: 15 September 2017

Final Accepted: 17 October 2017

Published: November 2017

Key words:-

Cocos nucifera, ethyl acetate, safety.

\section{Abstract}

Cocos nucifera is a tropical coastal plant. The ethyl acetate fraction of its aqueous root extract stimulates erythropoiesis. This work aimed to evaluate the biological tolerance of this fraction.

The extract fraction was administered to Wistar rats at a single dose of $2000 \mathrm{mg} / \mathrm{kg}$ body weight for Acute Oral Toxicity (OAT) or in daily doses of $200 \mathrm{mg} / \mathrm{kg}$ body weight for 28 days for Sub-Chronic Toxicity. (SCT), as recommended by the OECD. On day 0 , then on day 14 for OAT and day 28 for SCT, the rats were weighed and their blood was collected for tests. The liver balance was assessed by measuring transaminases AST and ALT, kidney balance by uremia and creatinine level and immune status by blood leukocyte count. These analyzes were supplemented by the histology of the liver, kidneys and spleen, an immune organ. The weight of rats, the balance of liver, kidney and immunity as well as these organs histology were not affected by either acute oral or sub-chronic toxicity tests, suggesting a lack of toxicity in the extract fraction. The ethyl acetate fraction of the root water extract of Cocos nucifera did not reveal any acute or sub-chronic oral toxicity. This effect could be related to its richness in flavonoids that are antioxidants. The study of biological tolerance deserves to be continued by the chronic toxicity test and clinical trials.

Copy Right, IJAR, 2017,. All rights reserved. 


\section{Introduction:-}

The Human populations used various plant species to find a cure for various diseases (Albiero, 2001). Thus, in traditional medicine, many plants were proposed for the anemia treatment. That were the cases of Magniferra indica leaves and stem (Ogbe et al., 2010), Telfairia occidentalis leaves (Alada et al., 2000), Schrebera swietenioides root bark (Pingali et al., 2015 ), Moringa oleifera leaves (Nwaehujor et al., 2015) and Jatropa tanjorensis (MacDonald et al., 2014).

The use of these plants requires not only a verification of their efficacy, but also and above all a control of their biological tolerance (Sofowora, 1982). Phytochemical screening of some of them sometimes revealed the presence of toxic compounds. This is the case of some Sorghum genus species that contain hydrocyanic acid, alkaloid hordenine and accumulates toxic levels of nitrate (Morton, 1981). Moreover the literature has documented several toxicity resulting from the use of herbs on many occasions (Joufang, 1994; O'Hara et al., 1998; Oduola et al., 2007).

The consumption of medicinal plants without studies of safety can result in several side effects that may affect different organs. The liver and kidneys are prime targets because they are involved in the degradation and excretion of a myriad of chemical compounds. Renal damage has been associated with the use of the medicinal plants in the treatment of different disorders, including diabetes mellitus (Mapanga and Musabayane, 2010).

Cocos nucifera Linn is an important member of the family Arecaceae found across coastal regions of the tropical and subtropical world (Harries et al, 1978). In West Africa this plant root is used to manage anemia (Tchogou et al, 2016). The present work aimed to test the safety of the aqueous extract ethyl acetate fraction of this root in experimental animal model.

\section{Materials and methods:-}

\section{Animal Material:-}

Animal material consisted of Wistar albino rats of average body weight $145 \pm 10 \mathrm{~g}$, having free access to water and food and acclimated to farming conditions from the pet of the Research Laboratory in Applied Biology (LARBA) located in the Polytechnic School (EPAC) of the University of Abomey-Calavi UAC) in Benin Republic. Breeding was done in a well ventilated room, with a day-night rhythm of $12 \mathrm{~h}$. The animals were kept in wire mesh cages with metal feeders and drinking troughs. Their daily diet was made from a mixture of food in the form of croquettes and marketed by Vet Services (Benin). The enclosure was regularly cleaned to ensure optimal development of the animals avoid infection.

\section{Identification and Preparation of Plant Material:-}

- Identification

Roots of Cocos nucifera were collected from Abomey Calavi in Benin during April 2015. The collected samples were identified and authenticated at the National Herbarium of Benin (HNB) at the University of Abomey Calavi. The samples were dried at moderate temperatures $\left(20-25^{\circ}\right.$ C), protected from moisture for four weeks. They were then crushed powder and stored in suitable containers at room temperature.

- Preparation of the aqueous extract

$50 \mathrm{~g}$ of root powder of Cocos nucifera were boiled in $500 \mathrm{ml}$ of distilled water in a $1000 \mathrm{ml}$ flask for 30 minutes. After cooling, the mixture is filtered using the Bushner. This operation is repeated for six times for a total mass of $300 \mathrm{~g}$. The filtrate (the aqueous phase) obtained is recovered and stored in a refrigerator in a jar for liquid-liquid extraction (first fractionation step). 
- Fractionation of the extract

Liquid-liquid extraction consists in passing a substance from a solvent, from which it is often difficult to separate, to another (called extraction solvent), from which it will be easily isolable. This operation, usually carried out by stirring, is possible provided that the two solvents are very little or no miscible with one another. But extraction is never $100 \%$, there are always molecules of the compound to be extracted in the solvent in which it is less soluble.

The Liquid-liquid was obtained by successive partitions with solvents of increasing polarity (hexane and ethyl acetate) according to the protocol of Koudoro et al. (2014).

In a separatory funnel, was added to the aqueous extract solution the appropriate volume of extraction solvent. After vigorous agitation, the mixture was allowed to settle. After decantation, the two phases were separated by collecting the lower phase (aqueous phase) in a flask and the upper phase (organic phase) in another. The aqueous phase was re-poured into the separating funnel before repeating the following steps. After each extraction step, the organic phases were combined, which constituted the fraction in a jar.

The liquid-liquid extracts obtained was then evaporated using a rotary evaporator at a temperature according to the solvents of polarity. The extractant phase was re-sealed and solidified in an oven at $40^{\circ} \mathrm{C}$. The dry residue obtained was reduced to powder and stored in a refrigerator in a brown flask. The yield of the fraction was calculated by the following formula:

\section{Acute toxicity test:-}

$$
\mathrm{R}=\frac{\text { Mass of fraction }}{\text { Mass of powder }} \times 100
$$

Acute toxicity test was carried out as recommended by the guideline 423 of the Organization for Economic Cooperation and Development for the testing of chemicals (OECD, 2002).

The substance was tested in a sequential process in which three animals including multiparous females and no pregnant aged 8 to 12 weeks are used at each stage. The absence or the manifestation of substance related mortality in a group dosed at a step would determine the next step. The initial dose was selected from the following four doses: 5, 50, 300 and $2000 \mathrm{mg} / \mathrm{kg}$ body weight. We administered by gavage to animals $2000 \mathrm{mg}$ of Cocos nucifera ethyl acetate extract fraction $/ \mathrm{kg}$ body weight. The animals were observed carefully during the four (4) hours and then daily for 14 days. They were weighed and blood was collected by orbital puncture at the start of the experiment and then after 14 days.

\section{Sub-chronic toxicity tests:-}

Five Wistar rats received the Cocos nucifera ethyl acetate extract fraction at $200 \mathrm{mg} / \mathrm{kg}$ body weight, daily for 28 consecutive days by gavage (Biswas et al., 2010). They were weighed and blood was collected by orbital puncture at the start of the experiment and then after 28 days.

\section{Blood tests:-}

Biochemical parameters such as uremia and serum creatinine were doses to explore renal function. Transaminases AST and ALT were assayed for liver function. The WBC count was performed as hematological parameter. 


\section{Histology:-}

At the end of the experiment, the animals were dissected. The liver, the kidney and the spleen were removed, fixed in Bouin solution, and embedded in paraffin. The specimens sections ( 5 $\mu \mathrm{m})$ were mounted on glass slides, deparaffinated, and hydrated. For histological analysis, sections were stained with hematoxylin and eosin (H\&E), following a standard protocol (Sènou et al, 2009). The pictures were taken at 400X magnification.

\section{Statistical Analysis:-}

The means were compared using Mann-Whitney test. The significance level was set at 5\%.

\section{Results and discussions:-}

The ethyl acetate fraction of Cocos nucifera root aqueous extract was not acutely toxic:-

Acute oral toxicity was assessed by measuring of rat weight as physical parameter, transaminases AST and ALT as liver parameters, uremia and creatinine as kidney parameters and number of white blood cells as immune parameter (Table 1).

Table 1:- Acute oral toxicity

\begin{tabular}{|l|l|l|l|l|}
\hline Parameters & Means at D0 & Means at D14 & Pvalue & Difference \\
\hline Rat weight (g) & $150 \pm 5$ & $152 \pm 5$ & 0.7 & no significant \\
\hline Uremia (g / L) & $0.53 \pm 0.15$ & $0.63 \pm 0.15$ & 0.5 & no significant \\
\hline Creatinine (mg /L) & $9 \pm 2$ & $8 \pm 2$ & 0.4 & no significant \\
\hline Transaminase AST (IU / L) & $116 \pm 8$ & $108 \pm 10$ & 0.4 & no significant \\
\hline Transaminase ALT (IU / L) & $65 \pm 10$ & $54 \pm 8$ & 0.2 & no significant \\
\hline White Blood Cells (G/L) & $6.9 \pm 1.3$ & $7.4 \pm 1.1$ & 0.8 & no significant \\
\hline
\end{tabular}

The mean weight of the rats was $150 \pm 5 \mathrm{~g}$ at day 0 and did not significantly change at day 14 , suggesting no disturbance of the physical parameters of the rats.

The mean uremia and creatinine levels were $0.53 \pm 0.15 \mathrm{~g} / \mathrm{L}$ and $9 \pm 2 \mathrm{mg} / \mathrm{L}$, respectively. They did not significantly change at day 14 suggesting a lack of renal function impairment.

The transaminases AST and ALT were respectively $116 \pm 8 \mathrm{IU} / \mathrm{L}$ and $65 \pm 10 \mathrm{IU} / \mathrm{L}$ at day 0 . They both experienced a slight decrease on Day 14, which, however, was not statistically significant, suggesting a protection of liver function.

The mean number of blood leukocytes was $6.9 \pm 1.3 \mathrm{G} / \mathrm{L}$. It did not significantly change on day 14 , suggesting no disturbance of immune function.

The ethyl acetate fraction of Cocos nucifera root aqueous extract was not toxic in subchronic state:-

Subchronic oral toxicity was assessed by the same parameters previously measured for acute oral toxicity, namely: rat weight, transaminases, and uremia, creatinine, and white blood cell counts (Table 2).

Table 2:- Subchronic toxicity

\begin{tabular}{|l|l|l|l|l|}
\hline Parameters & Means at D0 & Means at D14 & Pvalue & Difference \\
\hline Rat weight (g) & $149 \pm 9$ & $153 \pm 7$ & 0.4 & no significant \\
\hline Uremia (g / L) & $0,65 \pm 0.08$ & $0.60 \pm 0.09$ & 0.4 & no significant \\
\hline Creatinine (mg /L) & $8 \pm 2$ & $8 \pm 1$ & 0.8 & no significant \\
\hline Transaminase AST (IU / L) & $120 \pm 9$ & $117 \pm 11$ & 0.6 & no significant \\
\hline Transaminase ALT (IU / L) & $66 \pm 10$ & $62 \pm 12$ & 0.5 & no significant \\
\hline White Blood Cells (G/L) & $7.0 \pm 1.3$ & $7.8 \pm 1.1$ & 0.3 & no significant \\
\hline
\end{tabular}


The mean weight of the rats was $149 \pm 9 \mathrm{~g}$ at day 0 . There was a slight increase on day 28 , which however was not statistically significant suggesting no physical involvement of the rats.

The mean urea and creatinine levels were $0.65 \pm 0.08 \mathrm{~g} / \mathrm{L}$ and $8 \pm 2 \mathrm{mg} / \mathrm{L}$, respectively. They did not significantly change on day 28, suggesting a lack of renal function impairment.

The mean AST and ALT transaminases were respectively $120 \pm 9 \mathrm{IU} / \mathrm{L}$ and $66 \pm \mathrm{IU} / \mathrm{L}$ at day 0 . They did not significantly change at day 28 , suggesting an absence of liver function impaired.

The mean number of blood leukocytes was $7.0 \pm 1.3 \mathrm{G} / \mathrm{L}$ at day 0 . It did not significantly change on day 28 , suggesting no disturbance of immune function.

The ethyl acetate fraction of the aqueous extract of Cocos nucifera did not alter the hepatic, renal and splenic parenchyma in the acute or sub-chronic state
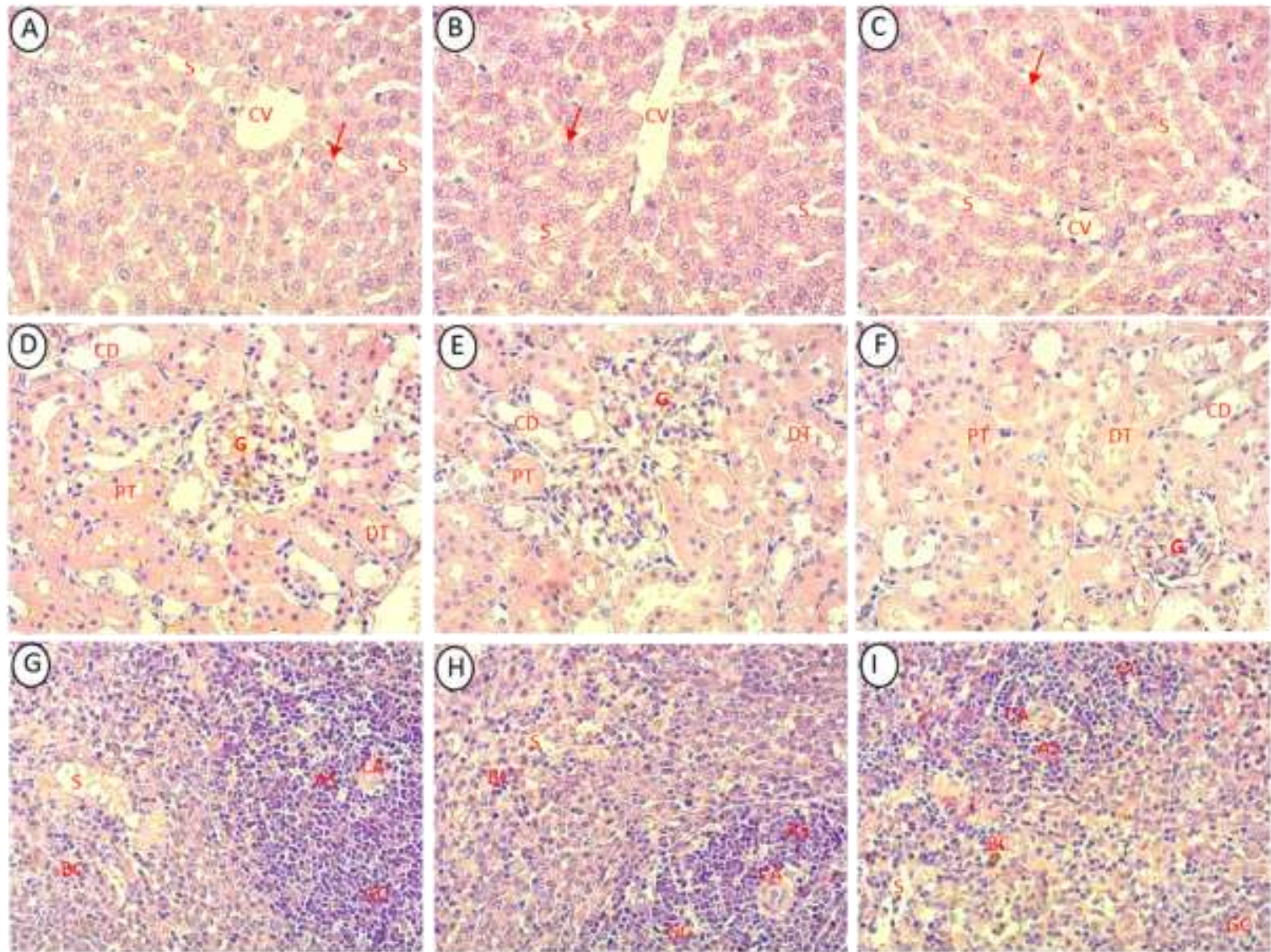

Magnification: $400 \mathrm{X}$

Figure 1: Hepatic, renal and splenic histology of rats in acute and sub-chronic toxicity tests.

In the acute (Figure 1B) or sub-chronic (Figure 1C) toxicity test, liver parenchymal architecture was typical of as that of untreated rats (Figure 1A). Hepatocytes (arrows) had no visible atypia and were well ranged radial around the central veins (V). Between these rays, the sinusoids (S) were clearly visible. 
Similarly, in the acute (Figure 1E) or sub-chronic (Figure 1F) toxicity test, the kidneys had the typical parenchyma of untreated rats (Figure 1D). The glomeruli $(\mathrm{G})$, proximal tubules (PT), distal tubules (DT) and collecting ducts (CD) displayed the characteristic appearance without visible abnormalities.

The splenic parenchyma was also typical at acute (Figure $1 \mathrm{H}$ ) or sub-chronic (Figure 1I) oral toxicity test as in untreated rats (Figure 1G). Peri-arteriolar sheaths (AS) of lymphocytes around the central arteries (CA) and the germinal centers (GC) of the white pulp were typical. It was the same for the sinusoids (S) and the Billroth cords (BC) of the red pulp.

Cocos nucifera L. was a tropical plant very common in coastal areas (Harries et al, 1978). Its roots were used as an effective plant to treat anemia (Tchogou et al, 2016). The phytochemical screening of the aqueous extract of these roots having revealed many families of chemical compounds, it became interesting to look for, by fractionation of the extract, the compound groups carrying the hematopoietic activity. The ethyl acetate fraction of the aqueous root extract of Cocos nucifera showed significant erythropoietic activity (Sènou et al., 2017). In this work, we investigated the biological tolerance of this fraction of root extract by acute and subchronic oral toxicity tests as recommended by the OECD (2002). The parameters analyzed were the weight of rats, hepatic, renal, immune and balances as well as histology of the organs.

The ethyl acetate fraction of Cocos nucifera root did not alter the behavior and weight of rats in acute or sub-chronic oral toxicity tests. This observation was also made with the crude root extract (Tchogou et al., 2017) and with the coconut green shell liquid or its butanoic extracts (Costa et al, 2011).

In the acute or sub-chronic oral toxicity tests, the ethyl acetate fraction did not affect liver function, ASAT and ALAT transaminases did not increase and hepatic parenchyma remained typical. This observation was made with the crude extract of this root (Tchogou et al., 2017). In fact, a hepatoprotective effect was also observed with the water of Cocos nucifera nut, which lowered the ASAT and ALAT transaminases in a model of carbon tetrachloride poisoning (Evans et al, 2001).

The renal balance outcome of uremia and creatinine did not change in the acute or sub-chronic oral toxicity tests, suggesting that the ethyl acetate fraction of the extract was not nephrotoxic. The observation was confirmed in histology which showed a renal parenchyma with glomeruli, proximal and distal tubules as well as collecting ducts normal-looking. The same observations were made with the crude extract of this root (Tchogou et al., 2017). A protective effect of renal function was also observed with Cocos nucifera nut water, which lowered uremia and serum creatinine in a model of ethylene glycol-induced nephropathy (Gandhi et al, 2013).

The immune balance assessed by the blood leukocytes count was not affected with acute or subchronic oral toxicity tests. The histology of the spleen, a peripheral immune organ, was not modified, confirming the previous observations made with the crude extract (Tchogou et al., 2017). Moreover, an anti-inflammatory effect was noted with the ethyl acetate extract of Cocos nucifera fiber following a local inflammation induction by xylene in animal experiments (Silva et al, 2009). 
Ethyl acetate mainly isolates flavonoids (Manjusha et al., 2013; Koudoro et al., 2014) which are a family of chemical compounds with a broad spectrum of pharmacological activities and low toxicity (Wang et al., 2006; Wang et al., 2011, Petrick et al., 2015). The lack of toxicity of the root aqueous extract may be related to the known cytoprotective effect of several members of this family against oxidative stress (Bigoniya et al., 2013, Fang, et al. ., 2016).

\section{Conclusion:-}

The ethyl acetate fraction of the root water extract of Cocos nucifera appears to protect the vital functions of the body. This property could be related to its wealth of flavonoids that are powerful antioxidants. However, the study of biological tolerance deserves to be continued by chronic toxicity tests and clinical trials.

\section{References:-}

1. Alada, A.R.A., (2000). The hematological effect of Telfelria occidentalis diet preparation. African Journal of Biomedical Research, 3, 185-186.

2. Albiero, A.L.M., E.M. Bacchi, K.S.M. Mourão, (2001). Acta Scientiarum Maringá. 23(2), 549-560.

3. Biswas, M., B. Kar, T.K. Karan, S. Bhattacharya, R.B.S. Kumar, A.K. Ghosh, P.K. Haldar, (2010). Acute and sub-chronic toxicity study of Dregea volubilis fruit in mice. J. Phytol. 2(8): 6-10.

4. Costa, C.T.C., C.M.L. Bevilaqua, D.C.S. Nascimento, D.C.S. Nunes-Pinheiro, T.A. da Rocha, A.L.F. CamurçaVasconcelos, L.M.B. de Oliveira, (2011). Toxicological activity evaluation of Cocos nuciferal In experimental models. Ciência Animal, 21(1), 35-44.

5. Evans, P., B. Halliwell, (2001). Micronutrients: oxidant/antioxidant status. Br J Nutr; 85(2), S67-S74.

6. Fang, A.N., W. Shulin, Y. Danhua, G. Yuewen, W. Shuhua, (2016). Attenuation of Oxidative Stress of Erythrocytes by Plant-Derived Flavonoids, Orientin and Luteolin. Hindawi Publishing Corporation EvidenceBased Complementary and Alternative Medicine, ID 3401269 http://dx.doi.org/10.1155/2016/3401269

7. Gandhi, M., M. Aggarwal, S. Puri, S.K. Singla, (2013). Prophylactic effect of coconut water (Cocos nucifera L.) on ethylene glycol induced nephrocalcinosis in male wistar rat. IntBraz J Urol, 39, 108-117.

8. Harries, H.C., (1978). The evolution, dissemination and classification of Cocos nucifera L.The Botanical Rev., 44, 265-319.

9. Jou-fang, D., (1994). Clinical toxicity of Herbal medicine in Taiwan. $7^{\text {th }}$ International conference on Health problems related to the Chinese.

10. Koudoro, Y.A., L.S.O. Dedomè, M. Yovo, C.P. Agbangnan-Dossa, P.F. Tchobo, G.A. Alitonou, F. Avlessi, D.C.K. Sohounhloué, (2014). Chemical characterization, antiradical and antibacterial activities of extracts of the root bark of Cochlospermum planchoni of Benin. International Journal of Innovation and Applied Studies 7(4), 1582-1594.

11. Mac Donald, I., (2014). Anti-anemic activity of Jatropha tanjorensis Ellis and Saroja in Rabbits. Journal of Medicinal Plants Studies, 2(1), 64-72.

12. Manjusha, S., M. AbrarHussain, S. Manik, Y.M. Mohhd, Q. Sumeerah, I.M. Mohd, C. Yogesh, (2013). Phytochemical Screening and in-vitro Antioxidant Activity Isolated Bioactive Compounds from Tridax procumbens Linn. Pakistan Journal of Biological Sciences, 16(24), 1971-1977.

13. Mapanga, R.F., C.T. Musabayane, (2010). The renal effects of blood glucose-lowering plant-derived extracts in diabetes mellitus - an overview. Renal Failure, 32, 132-138.

14. Morton, J.F., (1981). Atlas of Medicinal Plants of Middle America Bahamas to Yucatan.

15. Nwaehujor, C.O., (2015). Effect of Moringa oleifera Lam. Ethanol leaf Extract on Hematology in Phenylhydrazine-induced Anemic Albino Wistar Rats. American Journal of Pharmacological Sciences, 3(3), 67-73.

16. O.E.C.D., (2002). Guidelines for the Testing of Chemicals, Section 4. Test No. 423: Acute Oral toxicity - Acute Toxic Class Method Pages: 14 ISBN: 9789264071001 (PDF) DOI: 10.1787/9789264071001

17. O’Hara, M., D. Kiefer, K. Farrel, K. Kemper, (1998). A review of 12 commonly used medicinal herbs. Arch. Fam. Med. 523-536.

18. Okigbo, R.N., U.E. Eme, S. Ogbogu, (2008). Biodiversity and Conservation of Medicinal and Aromatic Plants in Africa. Biotechnology and Molecular Biology Reviews, 3, 127-134. 
19. Oduola, T., G.B. Popoola, O.G. Avwioro, T.A. Oduola, A.A. Ademosun, M.O. Lawal, (2007). Use of Jatropha gossypifolia stem latex as a haemostatic agent: how safe is it? J. Med. Plants Res. 1(1), 014-017.

20. Ogbe, R.J., G.I. Adoga, A.H. Abu, Antianemic potentials of some plant extracts on phenylhydrazine-induced anemia in rabbits. Journal of Medicinal Plants Research, 4, 680-684.

21. Okigbo, R.N., U.E. Eme, S. Ogbogu, (2008). Biodiversity and conservation of medicinal and aromatic plants in Africa. Biotechnol. Mol. Biol. Rev. 3(6), 127-134.

22. Olaleye, M.T., (2007). Cytotoxicity and antibacterial activity of methanolic extract of Hibiscus sabdariffa. Journal of Medicinal Plants Research, 1(1), 009-013.

23. Petrick, J.L., S.E. Steck, P.T. Bradshaw, (2015). Dietary intake of flavonoids and oesophageal and gastric cancer: incidence and survival in the United States of America (USA), British Journalof Cancer, 112, 12911300.

24. Pingali, P.S., P. Srinivasi, M.B. Reddy, (2015). Study of Anti- Anemic Effect of Schreberaswiet enioides Roxb. in rat models. Asian Journal of Pharmaceutical and Clinical Research, 8(5), 260-263.

25. Senou, M., M.J. Costa, C. Massart, M. Timmesch, C. Khalifa, S. Poncin, M. Boucquey, A.C. Gérard, J.N. Audinot, C. Dessy, J. Ruf, O. Feron, O. Devuyst, O. Guiot, J.E. Dumont, S.J. Van, M.C. Many, (2009). Role of caveolin-1 in thyroid phenotype, cell homeostasis, and hormone synthesis: in vivo study of caveolin-1 knockout mice. Am J Physiol Endocrinol Metab, 297, E438-E451.

26. Sènou, M., A.P. Tchogou, C.P. Agbangnan-Dossa, T.V. Dougnon, P. Ogué, A. Agossadou, A. Lalèyè, F. Loko, A. Agbonon, A. Sèzan, (2017). Efficacy of ethyl acetate fraction of Cocosnucifera's aqueous extract on the treatment of anemia. International Journal of Pharmaceutical Science Invention, 9(9), 44-51.

27. Silva, L.C.R., D.C.S. Nunes-Pinheiro, S.M. Morais, B.E. Lopes-Neto, G.J. Santos, (2009). Avaliac ão toxicologicale efeito do extratoacetato de etila da fibra de Cocos nucifera L. (Palmae) sobre a respostainflamatória in vivo. Rev Bras Plantas Med; 11, 429.

28. Sofowora, A., (1982). Medicinal Plants and Traditional Medicine in Africa. John Wiley and Sons Limited, New York, Toronto, pp. 80-96.

29. Stamler, J., D. Welthworth, J.D. Neaton, (1986). Is there a relationship between serum cholesterol and risk of premature death from coronary heart disease and grade? J. Am. Med. Assoc., 253, 2823-2826.

30. Tchogou, A.P., M. Sènou, T.V. Dougnon, A. Agossadou, F. Assogba, E.G. Kinsiclounon, E. Ewedjè, C.P. Agbangnan-Dossa, J. Gbénou, A. Lalèyè, F. Loko, (2016). The Aqueous Extract of Cocos nucifera L. (Arecaceae) Effectively Treat Induced Anemia. Experimental study on Wistar Rats. International Journal of Biology, 8(3), 5-54.

31. Tchogou, A.P., M. Sènou, C.P. Agbangnan-Dossa, A. Agossadou, F. Assogba, T.V. Dougnon, J.R. Klotoé, J. Gbénou, A. Sèzan, A. Lalèyè, F. Loko, (2017).Test of the safety of Cocos nucifera L. (Arecaceae) root aqueous extract. Journal of Chemical, Biological and Physical Sciences.7(1) 282-291.

32. Wang, X.C.F.M.W., S.P. Li, H.L. Wang, "Anti-apoptotic effect and the mechanism of orientin on ischaemic/reperfused myocardium," Journal of Asian Natural Products Research, 8(3), 265-272.

33. Wang, Q., L.H. Chang, H.M. Tang, (2011). "Extraction of the flavonoids and its research progress in biological activity," Journal of Hebei United University Natural Science Edition, 33(1), 110-117. 